\title{
Stability through Cycles
}

\author{
Bert de Groot \\ Philip Hans Franses \\ Econometric Institute \\ Erasmus University Rotterdam
}

Econometric Institute Report 2006-07

\begin{abstract}
Economic variables like GDP growth, employment, interest rates and consumption show signs of cyclical behavior. Many variables display multiple cycles, with lengths ranging in between 5 to even up to 100 years. We argue that multiple cycles can be associated with long-run stability of the economic system, provided that the cycle lengths are such that interference is rare or absent. For a large sample of important variables, including key variables for the US, UK and the Netherlands, we document that this is indeed the case.
\end{abstract}

Key words: Long waves, business cycles, economic stability, Fibonacci JEL code: 011

March 272006

\section{Acknowledgements}

We sincerely thank Hens Steehouwer for allowing us to use the data that he collected for this PhD thesis. We also thank Lotje Kruithof for excellent research assistance and Richard Paap for writing the Eviews program that we replicate in the appendix. 


\section{Introduction}

Economies of industrialized countries show cyclical patterns. Recessions since WWII seem to emerge every 8 to 10 years, which is usually associated with the business cycle, and long swings like the well-known 55 year Kondratieff cycle can be observed for a variety of variables. In fact, many economic variables seem to have even more than one cycle.

Roughly speaking, there are two views on the presence of one or more economic cycles. The first is that cycles are caused by shocks that are exogenous and largely unpredictable. These shocks can be associated with wars, technological innovations, fashion, generational conflicts and many more. The response of economic entities to such shocks sometimes can last a while, that is, some shocks are very persistent. Approximate models for such variables, at least in reduced form, are typically of the autoregressive (AR) kind, where the parameters take such values that some of the solutions of the autoregressive polynomial are complex-valued (that is, they are functions of $i^{2}=-1$ ), see Steehouwer (2005) and the literature cited therein.

Basically this view at cycles assumes that in the absence of shocks, there should be no cycles. This assumption is extrapolated when making forecasts, as when long-run forecasts are made from AR models with complex solutions, eventually these forecasts tend towards the mean of the time series under scrutiny, and hence by definition the cyclical patterns disappear.

A second premise that follows from this view is that when economic variables have multiple cycles with various lengths, these multiple cycles are caused by exogenous shocks that apparently also display multiple cycles. Indeed, De Groot and Franses (2005) document that technological innovations show multiple cycles, and perhaps, due to such cycles in shocks, economic variables also have cycles. This argument however assumes that such innovations are truly exogenous. As already suggested in De Groot and Franses (2005), this is doubtful as it is most likely that economic progress and technological innovations, and maybe even shocks like wars and generational conflicts, are somehow intertwined, even so that it is difficult to state which type of shock is truly exogenous. De Groot and Franses (2005) document that a time series of the technological innovations experiences similar cycles (and of similar length) as those reported for major economic variables. 
A second view on the presence of economic cycles, which is also the view taken up in our current paper, is that, loosely speaking, there have always been multiple cycles and there always will be. Hence, these cycles are not fully stochastic and caused by external shocks, but are in fact partly deterministic. This is perhaps not so much of novelty, but the main new argument we make is that overall economic growth patterns are stable due to the very fact that there are multiple cycles. Basically, the argument is as follows. A first notion is that if there are economic cycles it cannot be a single, say lengthy, cycle. Indeed, if we were all to know how this cycle would look like (say each 55 years a severe dip), we would behave accordingly or we would try the cycle to stop, or we would try to dampen its amplitude. With these last two efforts, governments issue policies and producers and consumers start to behave differently, and hence they start to behave anti-cyclically. This in turn can lead to some trembling, which in turn leads to other cycles.

The main characteristic of the cycles, though, should be that these cycles do not or do almost not interfere. If that would happen, that is, that cycles at the same time could take their lowest values, then that would give an opening for an eruption or substantial crisis, perhaps one that can never be undone. Hence, for economies to be stable, it is preferable that they have cycles and that their interference does not lead to an enormous peak or dip because all cycles would peak and dip at the same time. Ideally one would like to see a "smooth" development.

A first impression of this phenomenon could be seen from De Groot and Franses (2005) where a graph with all the cycles in innovations series seems rather erratic but stable, while there are five major underlying cycles. Hence, we conjecture that cycles in economic variables have lengths such that economies are resistant enough to major shocks. So, there are shocks, and they do have an impact, but due to the constellation of the cycles there will not be any instability.

It should be remarked that when this second view, that is also ours, is adopted, models should include descriptions of these cycles as these cycles in the sample should be extrapolated into the future. In other words, if one believes in multiple cycles of a deterministic nature, one should also generate long-run forecasts with such cycles ${ }^{1}$.

\footnotetext{
${ }^{1}$ We assume that the nature of these cycles does not change over time, that is, there are no changes in amplitude or length. Allowing for such changes complicates the econometric analysis quite
} 
The outline of our paper is as follows. In Section 2 we briefly summarize the relevant findings on cycles in economics and we mention a few economic theories that seek to explain such observations. In Section 3 we outline the main ideas behind our notion that economies can be stable if they experience multiple cycles, where these cycles have lengths such that they do not interfere. To see if we find evidence of such non-interference in empirical data, in Section 4 we consider 33 series of 3 countries and few related ones. Our results are remarkable. We document a total number of 90 cycles. The best way to describe the cycle lengths turns out to be a mixture of four normal distributions, with mean values around 10, 28, 58 and 92. Note that these values are close to the Fibonacci numbers 8, 21 (34), 55 and 89, which we believe would entail cycle lengths with maximum stability. Indeed, for cycles of length 21 and 55 to interfere, one would need 21 times 55 years of data. In Section 5 we conclude with a review of the main findings and we provide openings for discussion by summarizing the limitations of our study as well as the challenges for further research.

\section{Cycles in the economy}

Economists follow different approaches to explain cyclical economic development. In this section we give a concise overview of the most relevant theories.

\section{One cycle}

Economists view economic development as being cyclical. Over the years many different types of cycles have been hypothesized. Some well-known examples are the 3 to 4 year Kitchin (1923) inventory investment cycle, the 7 to 11 year Juglar (1860) cycle which focuses on investment in machines, the 15 to 25 year Kuznets (1930) cycle in migration and investment in construction and, of course, the controversial 48 to 60 year Kondratieff (1928) cycle which mainly concerns structural economic development. Researchers like Goldstein (1988) and Modelski and Thompson (1987)

substantially. Moreover, as of yet we would not have any firm arguments which causal forces could establish such changes. 
[(1996)], claim that there are even longer 110 to 150 year cycles of hegemony. Most of these ideas assume the presence of a single cycle.

\section{Multiple Cycles}

The main idea on the multiplicity of cycles goes as far back as Schumpeter. In his seminal work Business Cycles (1939), he elaborates on cyclical development theories and he proposes the concept of a multiple cycle economy in which innovation is a driving force. In De Groot and Franses (2005) we substantiate this claim by showing that innovations experience similar cycles as economic variables do.

Schumpeter expects the number of active cycles to be indefinite. Note that the famous three cycle schema in which he combines a Kitchin, a Juglar and a Kondratieff is a simplification and is strictly for illustrative purposes only. We argue that there is no reason to believe that the cycles fit into one another, that is, one cycle is twice another one, say. In fact, as we conjecture below, the cycles should better not fit into each other as that would allow for periods of serious instability.

Schumpeter gives three reasons for the existence of multiple cycles. The first reason is that different innovations take varying lengths of time to be absorbed into the economy. Secondly, he states that major driving innovations do not emerge in their final form or diffuse synchronously throughout the whole economy. The consequences of some innovations are thus propagated in steps. Finally, Schumpeter recognizes that major innovations can have a far reaching influence on the economy. In order to reap the benefits enabled by these types of innovations, businesses and even society as a whole have to adapt step by step. Schumpeter does not hint at cycles with a strict periodicity and regularity but at unique epochs which each have their own unique driving major innovations, exogenous disturbances and constellation of cycles (ibid, pages 166-168). For the sake of simplicity Schumpeter only analyzes the three cycle case, disregards the effects of external disturbances and assumes successful correction for seasonality and growth. In reality he does not expect the cycles to have a strict sine form or exact internal regularity.

Kuczynski (1978) discerned cycles of 2, 8, 9, 13, 23 and 60 years, see also van Duijn (1983, pp 170-171). Kuczynski focused on real economic growth of production 
and also used inventions and innovation data. Using spectral analysis he found a variety of waves with different lengths. He could not explain the theoretical background of his findings.

Some researchers found results that hinted towards the Schumpeterian multiple cycle approach. Haustein and Neuwirth (1982) document a whole range of waves of different lengths which they all ascribe to innovations. They have similar findings as Kitchin, Juglar, Kuznets and Kondratieff. Haustein and Neuwirth group their cycles around certain averages, their spectral analysis reveals cycles of: 53 (53.3), 40, 32 (26.7, 32 and 33.3), 20 (16, 16.7, 20 and 22.6), 13 (10.7, 11.4, 12.3, $12.5,13,13.3,14.3$ and 14.5$)$ and around $7(5.9,6.1,6.3,6.7,6.9,7,7.3,7.6,8.0,8.4$ and 8.9) years. According to Haustein and Neuwirth these cycles are not strictly regular and periodic and they prefer to call them "historical periods" and "quasicycles". They connect the cycles which have a corresponding length to the four well known cycles from the literature and although they find more than one cycle they do not explicitly comment on the existence of a multi-cycle structure in innovations or in the economy.

In his research, van Duijn (1983) elaborates on Schumpeter's multiple cycle idea. He uses Schumpeter's three-cycle scheme concept to develop a scheme of his own. In addition to the three cycles used by Schumpeter, he also incorporates the 1525 year Kuznets cycle in his theory. Van Duijn acknowledges that: "All four cycles exist simultaneously." His schema is as follows (p 6): "1 Kondratieff $=3$ Kuznets $=6$ Juglars $=12$ Kitchins." So, again there is the idea that shorter cycles should fit into longer ones. He recognizes that Schumpeter's three-cycle schema is a simplification, but states that it is a valuable depiction of reality nonetheless: "It is very tempting but also very simplistic to see economic development as the result of four thus interwoven cycles. Yet, simplistic as it may seem, there is some truth to this representation." Van Duijn mentions that the cycles most likely operate in an interlinked manner and that they are essentially driven by fluctuations in investment, even though basic innovations are needed to fuel this investment process.

Finally, Reijnders (1990) also acknowledges Schumpeter's multi-cycle hypothesis. He writes (p 3): "If it is conceivable that the business cycle is the effect of the economy's reaction to external disturbances it is also conceivable that distinct parts of it react differently. Several sub-systems may generate different adaptation processes of which every single one has a characteristic time path of its own. 
Consequently, macroeconomic motion can only be interpreted in terms of a multicycle concept." Reijnders (1990) furthermore states that the erratic patterns of economic development can at least partially be explained by the interplay between cycles of different lengths. He declares that the well known 'uni-cycles' exist, but not in the traditional way. According to him they are a part of the multi-cycle structure. Each cycle, both known and unknown, can be grouped into a domain which corresponds with their average duration. These arguments get somewhat closer to ours, as we will demonstrate in the next section.

\section{Stability and Cycles}

In this section we outline our thoughts on the nature of economic development. As others do, we conjecture that most economic variables cannot be described by a single cycle but by multiple cycles. Together, these longer and shorter cycles with different lengths and amplitudes form constellations of cycles within each of the variables. The constellations do not consist out of simple multiplications of shorter cycles but out of various independent cycles which run more or less in their own domain.

All cycles, when summed, give a representation of the economy. When taken together the cycles form an erratic pattern which resembles the oscillation, the growth and decline, of an economy.

Stability is an important feature of the economic system. The total set of cycles expresses stability. We will give two examples of the stability of the system as a whole. First, within the constellations the individual cycles all have an own domain. Second, the interferences of the cycles with different lengths and amplitudes counterbalance each other, hereby creating an inherently more stable system. The difference in lengths of the cycles provides that the system never fully implodes or explodes due to unforeseen shocks, which of course can still occur. This harmonic and cyclical development of the economy, alternating periods of prosperity and decline, is a token of stability of the economic system as a whole.

We accept that shocks and impulses are necessary to create cyclical behaviour. We also believe that those shocks and impulses will always exist. Individuals, firms and governments will always act and cause impulses and cause economic growth and decline. The economy will therefore always oscillate and will never tend towards a 
static equilibrium in the classical sense. There is simply no reason to believe why shocks would be absent in the future.

In conclusion, we do not consider the concept of a single big wave to be valid any longer. Erratic patterns can be decomposed into multiple shorter, smaller and longer, larger cycles. We believe that economic variables can be decomposed into a constellation of cycles.

Following the concept of multiple cycles, we take into consideration that, after decomposing an economic variable into a constellation of cycles, an underlying structure may be revealed. Indeed, in stable economies one might expect to find cycles that, taken together, do not cause enormous peaks or dips. Hence, it should be unlikely to find cycles of length 4,8 and 16 . In fact, to prevent that interferences of the cycles, would lead to enormous peaks and dips, because of the cycle length, an optimal set of cycle lengths would match with the numbers of the Fibonacci sequence, as cycles with lengths $8,13,21,34,55$ and 89 do not create that enormous peak or dip within a time span of thousands of years.

\title{
4. Empirical results
}

In this section we analyze the cyclical properties of 33 key variables for 3 industrialized countries, that is, the US, UK and the Netherlands, as well as 7 series for wages, prices and innovations that have been considered in related studies. The first database was kindly made available by Hens Steehouwer, and they appear in Appendix F of Steehouwer (2005). In Tables 1a and 1b we summarize the variables and the time spans in years. In Figures 1a, 1b and 1c, we give the graphs of first 33 series per country.

\author{
Insert Tables $1 \mathrm{a}$ and $1 \mathrm{~b}$ \\ Insert Figures $1 \mathrm{a}, 1 \mathrm{~b}$ and $1 \mathrm{c}$
}

Our research methodology is the same as outlined in De Groot and Franses (2005), where in that study the focus was on a count data variable, whereas we have continuous variables. All variables below are considered in stationary format. This 
means that some variables are first log-transformed and then first-order differenced to render growth rates (like the National Product Index and Population), while others are left intact (like the interest rates). We denote the final series as $Y_{t}$.

For each $Y_{t}$ we consider the following regression

$$
Y_{t}=\mu+\varepsilon_{t},
$$

where $\varepsilon_{t}$ has mean zero and common variance $\sigma^{2}$. Sometimes the $\varepsilon_{t}$ is replaced by

$$
u_{t}=\rho u_{t-1}+\varepsilon_{t}
$$

to capture prominent autoregressive dynamics. To translate this unconditional model to a conditional model that is useful for our purposes, we assume that

$$
\mu=\alpha+\sum_{i=1}^{C}\left[\beta_{1, i} \sin \left(\frac{2 \pi t}{C_{i}}\right)+\beta_{2, i} \cos \left(\frac{2 \pi t}{C_{i}}\right)\right],
$$

which is a harmonic regression model. In words, this model says that economic variables show cycles of length $C_{1}, C_{2}$, and so on. The amount of cycles is $C$. The unknown parameters in this model are $\alpha, \beta_{1, i}, \beta_{2, i}$, and notably $C_{i}$.

An important empirical decision to be made is the amount of cycles that can be discovered in the data. In a test regression we set $\mu$ at

$$
\mu=\alpha_{0}+\left[\beta_{1} \sin \left(\frac{2 \pi t}{C_{i}}\right)+\beta_{2} \cos \left(\frac{2 \pi t}{C_{i}}\right)\right]
$$

For $C_{i}=1,2$, and so on we run this test regression. The $R^{2}$ values of these regression models are stored. Next, the largest values are taken as starting values for the full nonlinear regression model in (1). An initial guess of the amount $C$ is obtained from the first 100 partial regressions, where all relatively large values are taken aboard. Usually, $C$ ranges from 2 to 7 at maximum. Next, $C$ times an $F$-test is performed for the joint significance of $\beta_{1, i}$ and $\beta_{2, i}$ for each $I=1,2, . ., C$. When we do this test we fix the relevant value of $C_{i}$ and treat it as known ${ }^{2}$. Deleting insignificant cycles, we end with the estimation results as they are documented in Tables $2 a, 2 b$ and $2 c$ for the first database, and in Table $2 \mathrm{~d}$ for the second set of seven series.

Insert Tables $2 \mathrm{a}, 2 \mathrm{~b}, 2 \mathrm{c}$ and $2 \mathrm{~d}$

\footnotetext{
${ }^{2}$ We are aware of the fact that under the joint null hypothesis of $\beta_{1, i}$ and $\beta_{2, i}$ is zero, the parameter $C_{i}$ is not identified. Hence, this situation involves the familiar Davies (1977) problem. There are various solutions possible here, but for the sake of simplicity we stick to the current approach and leave such solutions for further work.
} 
For the USA in Table 2a, we find (out of the eleven series) three series with 4 cycles (National Product Index, Industrial Production Index, and Employment), where there is a strong resemblance between the cycle lengths. For four series we find just 1 cycle (the two Interest rates, Population and Corporate Bond Yield), where also these cycles are very similar in length (around 50-65 years). The results for the UK and the Netherlands are qualitatively similar, as are also the results in Table $2 \mathrm{~d}$. We now turn to an analysis of all 70 documented cycles for the first database (Tables 2a-2c), and of all 90 cycles if we take the results in all tables together.

\section{Insert Figures $2 \mathrm{a}$ and $2 \mathrm{~b}$}

In Figures $2 \mathrm{a}$ and $2 \mathrm{~b}$ we depict the histograms of all 70 and 90 cycles, respectively, that were documented in Tables $2 \mathrm{a}, 2 \mathrm{~b}, 2 \mathrm{c}$ and $2 \mathrm{~d}$. Clearly, this histogram shows multiple modes, and hence we proceed with estimating the parameters of a mixture of normal distributions. An example of the Eviews program that we use to estimate the means and variances of these distributions is given in the Appendix, as a courtesy to the reader. To find the number of distributions and the amount of communality across the variances, we try to estimate 8 versions. We allow for 3 and 4 normal distributions (as 2 was clearly rejected by the data), and we consider the cases where (i) the variance of all distributions is the same, (ii) are all different, or (iii) are the same for the distributions with the largest means. We also tried to estimate a mixture of 5 distributions, but that did lead to estimation problems.

\section{Insert Table 3}

Table 3 gives the Bayesian Information Criterion (BIC) value for each of these eight cases. The smallest BIC value is preferable, and we observe that this is the case for 4 normal distributions, where the last three distributions have the same variance. This holds in both cases.

Insert Tables $4 \mathrm{a}$ and $4 \mathrm{~b}$

The estimation results for the 70 and 90 cycles appear in Tables $4 \mathrm{a}$ and $4 \mathrm{~b}$, and they must be read as follows. For the case of 70 cycles, the first distribution has a mean 
value of 10.3 and a variance of 3.5. The final column of Table $4 \mathrm{a}$ and $4 \mathrm{~b}$ gives the probability of a cycle being assigned to this distribution. Hence, with probability $0.576(0.483)$ a cycle is associated with that first distribution. That is, economic variables have with reasonably high probability a cycle with an average length of 10.3. Obviously, one reason for finding this high probability is that shorter cycles are easier to measure for relatively shorter spans of time series data than are longer cycles.

In sum, we obtain empirical evidence that economic cycle lengths, where we now focus on Table $4 \mathrm{~b}$, can be classified into four distinct groups, with cycle lengths on average of 10.3, 27.9, 58.3 and 91.9. Again, and similar to the findings in De Groot and Franses (2005), we find cycle lengths that are remarkably close to Fibonacci numbers, here 8, 21 (34), 55 and 89. In fact, with the estimation results in Table 4a, we can compute that 8 is 0.66 standard errors away from 10.3, 21 is 0.59 standard errors away from 25.7, and 55 and 89 are just 0.34 and 0.38 standard errors away, respectively. Of course, our findings are no proof of the link between Fibonacci numbers and "optimal" cycle lengths, but we believe that the correlation is striking. Mind the reader, we only have considered 70 (90) cycles for only a few countries.

\section{Conclusion}

The empirical results documented in this paper substantiate our argument that economic variables display multiple cycles, with cycle lengths that apparently do not interfere. The sum of all these cycles mimics erratic behavior, but underlying are constellations of cycles of such a nature that stability of economic variables is preserved. Hence, due to these sets of cycles, economies can handle exogenous shocks that might otherwise put them off balance. Some of these shocks, like key technological innovations, are shown to have similar constellations.

Hence, behind all this are forces that, without knowing and without purpose, establish stability. What are these forces? There are various literatures on fractals ${ }^{3}$,

\footnotetext{
${ }^{3}$ Mandelbrot $(1977,1983)$ created the concept of fractals. He proposed the name fractal for the non-euclidean geometry, which have a fractional dimension. Scale invariance and self-
} 
chaos $^{4}$, complex systems ${ }^{5}$ and ecological economics ${ }^{6}$ that seek an answer to questions like this one, but, to us, no useful overarching theory has been developed.

One of the potential limitations of our research is that it is largely empirical, and hence the outcomes heavily rely on the quality of the data and of the model. Indeed, more detailed data and also data for other countries could have led to other results although we tend to believe that our results are reasonably robust, as we have used various variables from various countries. What could have happened of course is that there are breaks in the data, and that we think we have measured cycles of length $\mathrm{x}$ while in reality they are of length $\mathrm{y}$, interrupted once in while for some reason. Future research where we allow the parameters in the models to be time-varying could be illuminating. Finally, if stability really is the key reason why we see certain cycles, then an analysis of highly unstable economies could be insightful, although there one might face the problem of having a shortage of reliable data.

organized criticality are terms that are central to the debate in complex systems and chaos theory. Complex systems may manifest themselves as temporal scale invariance or fractals, temporal scale invariance or flicker noise or $1 / \mathrm{f}$ noise where $\mathrm{f}$ is the frequency of a signal and power laws when there is scale invariance in the size and duration of events in the dynamics of the system.

${ }^{4}$ The word chaos describes the dynamics of systems which do not display any periodicity in their behaviour and are exponentially sensitive to change in their initial conditions. Chaos is very much related to Lorenz (1963) who discovered the simple set of non-linear differential equations to describe weather forecasting. An attractor can be a point in which case the system tends towards equilibrium.

${ }^{5}$ Bak, Tang and Wiesenfeld (1987) presented the principle of self-organized criticality. It is a principle which governs the dynamics of systems, leading them to a complex state characterized by the presence of fractal and power law distributions. The state is critical. Here it is the dynamics of the system itself which leads it to a scale free state, it is therefore selforganized. The introduced the classic example of the sandpile. Bak went on to show that fractal fluctuations show scale invariance or selfsimilarity Since a chaotic system has a short memory and therefore it does not remember where it was for very long it might not be a good approach to describe systems that must adapt and learn over time. The characteristics of selforganized -criticality however are: long term correlation, scale invariance and the absence of any fine tuning in signals. These qualities make self-organized criticality an attractive principle to explain the dynamics of scale free behaviour.

${ }^{6}$ Other lines of research are econophysics and ecological economics. Econophysics applies methods from physics to economics. This is a very recent field of research. Relevant studies are Mantegna and Stanley (2000), McCauley (2004), and Roehner (2002). Ecological economics applies concepts from ecology and biology to economics in a systemic framework, mostly by means of analogy. Mutatinovic $(2001,2002)$ is a proponent of this approach. 


\section{Appendix: The Eviews program}

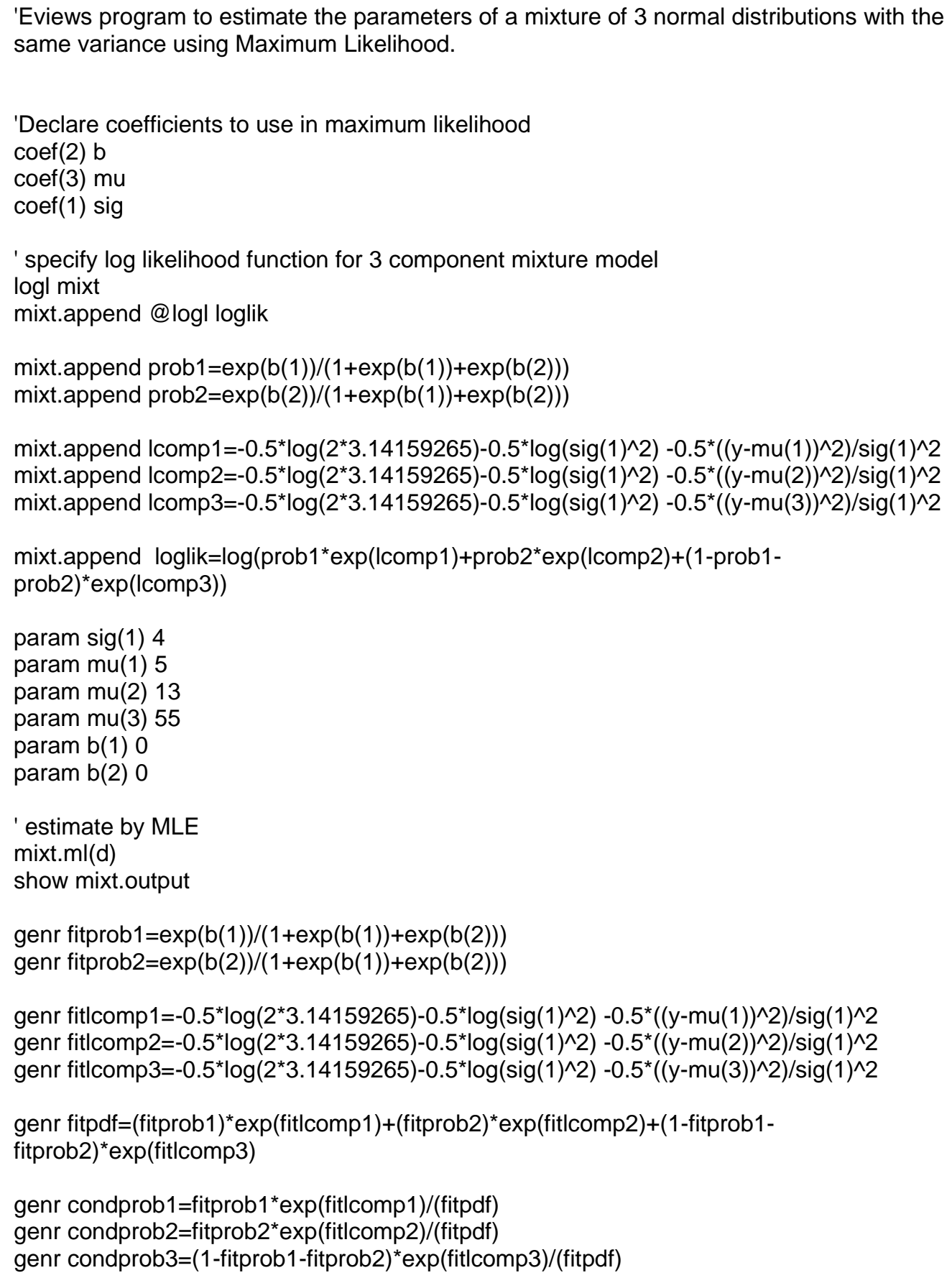


Table 1a: Variables taken from Steehouwer (2005)

\begin{tabular}{|c|c|c|}
\hline Country & Variable & Time span \\
\hline USA & $\begin{array}{l}\text { National product index } \\
\text { Industrial production index } \\
\text { Employment } \\
\text { Consumer price index } \\
\text { Wage index } \\
\text { Short interest rate } \\
\text { Long interest rate } \\
\text { Equity price index } \\
\text { Dividend yield } \\
\text { Population } \\
\text { Corporate bond yield }\end{array}$ & $\begin{array}{l}1870-1999 \\
1860-1999 \\
1890-1999 \\
1820-1999 \\
1786-1999 \\
1831-1999 \\
1798-1999 \\
1800-1999 \\
1871-1999 \\
1790-1999 \\
1857-1999\end{array}$ \\
\hline UK & $\begin{array}{l}\text { National product index } \\
\text { Industrial production index } \\
\text { Employment } \\
\text { Consumer price index } \\
\text { Wage index } \\
\text { Short interest rate } \\
\text { Long interest rate } \\
\text { Equity price index } \\
\text { Dividend yield } \\
\text { Population } \\
\text { Corporate bond yield } \\
\text { Equity total return index }\end{array}$ & $\begin{array}{l}1855-1999 \\
1855-1999 \\
1855-1999 \\
1600-1999 \\
1829-1999 \\
1820-1999 \\
1700-1999 \\
1800-1999 \\
1923-1999 \\
1870-1999 \\
1929-1999 \\
1800-1999\end{array}$ \\
\hline The Netherlands & $\begin{array}{l}\text { National product index } \\
\text { Industrial production index } \\
\text { Employment } \\
\text { Consumer price index } \\
\text { Wage index } \\
\text { Short interest rate } \\
\text { Long interest rate } \\
\text { Equity price index } \\
\text { Dividend yield } \\
\text { Population }\end{array}$ & $\begin{array}{l}1870-1999 \\
1921-1999 \\
1911-1999 \\
1813-1999 \\
1926-1999 \\
1828-1999 \\
1814-1999 \\
1816-1999 \\
1824-1999 \\
1839-1999\end{array}$ \\
\hline
\end{tabular}


Table 1b

Seven other variables and their sources

\begin{tabular}{lc}
\hline \hline Variable & Time span \\
\hline \hline Wholesale Price Index, UK & $1750-1975$ \\
Wholesale Price Index, France & $1798-1975$ \\
Wholesale Price Index, Germany & $1792-1918$ \\
Wholesale Price Index, US & $1801-1975$ \\
South English Real Wages & $1736-1954$ \\
South English Consumer Price Index & $1495-1998$ \\
Innovations & $1764-1976$ \\
\hline \hline
\end{tabular}

Sources: Goldstein (1988) for the price and wages series and Silverberg and Verspagen (2000) for innovations. 
Table 2a

Significant cycles for the US

\begin{tabular}{|c|c|c|c|c|c|c|c|}
\hline Variable & \multicolumn{7}{|c|}{ Cycles (standard errors) } \\
\hline National product index & $\begin{array}{l}6.27 \\
(0.06)\end{array}$ & $\begin{array}{l}7.64 \\
(0.08)\end{array}$ & $\begin{array}{l}15.5 \\
(0.38)\end{array}$ & $\begin{array}{l}19.7 \\
(0.53)\end{array}$ & & & \\
\hline Industrial production index & $\begin{array}{l}6.19 \\
(0.05)\end{array}$ & $\begin{array}{l}7.69 \\
(0.10)\end{array}$ & $\begin{array}{l}12.2 \\
(0.24)\end{array}$ & $\begin{array}{l}14.1 \\
(0.33)\end{array}$ & & & \\
\hline Employment & & $\begin{array}{l}8.81 \\
(0.11)\end{array}$ & $\begin{array}{l}13.1 \\
(0.23)\end{array}$ & $\begin{array}{l}20.7 \\
(0.38)\end{array}$ & & $\begin{array}{l}44.8 \\
(1.43)\end{array}$ & \\
\hline Consumer price index & & & & & $\begin{array}{l}28.5 \\
(0.59)\end{array}$ & & $\begin{array}{l}60.9 \\
(3.4)\end{array}$ \\
\hline Wage index & & & & $\begin{array}{l}18.2 \\
(0.29)\end{array}$ & $\begin{array}{l}29.9 \\
(0.72)\end{array}$ & & \\
\hline Short interest rate & & & & & & & $\begin{array}{l}66.7 \\
(4.4)\end{array}$ \\
\hline Long interest rate & & & & & & & $\begin{array}{l}60.2 \\
(4.0)\end{array}$ \\
\hline Equity price index & & & & $\begin{array}{l}19.2 \\
(0.48)\end{array}$ & & $\begin{array}{l}41.4 \\
(2.3)\end{array}$ & \\
\hline Dividend yield & $\begin{array}{l}4.78 \\
(0.04)\end{array}$ & & & & $\begin{array}{l}33.3 \\
(1.4)\end{array}$ & & \\
\hline Population & & & & & & $\begin{array}{l}51.5 \\
(2.9)\end{array}$ & \\
\hline Corporate bond yield & & & & & & & $\begin{array}{l}56.5 \\
(7.0)\end{array}$ \\
\hline
\end{tabular}


Table 2b

Significant cycles of the UK

\begin{tabular}{|c|c|c|c|c|c|c|c|}
\hline Variable & Cycles & (stands & ard errol & & & & \\
\hline National product index & & & $\begin{array}{l}12.2 \\
(0.17)\end{array}$ & $\begin{array}{l}14.0 \\
(0.24)\end{array}$ & & & \\
\hline Industrial production index & $\begin{array}{l}4.90 \\
(0.03)\end{array}$ & $\begin{array}{l}7.59 \\
(0.07)\end{array}$ & $\begin{array}{l}12.7 \\
(0.24)\end{array}$ & & & & \\
\hline Employment & & & $\begin{array}{l}12.7 \\
(0.20)\end{array}$ & $\begin{array}{l}25.4 \\
(0.53)\end{array}$ & & $\begin{array}{l}53.2 \\
(1.20)\end{array}$ & \\
\hline Consumer price index & & $\begin{array}{l}7.97 \\
(0.04)\end{array}$ & & & $\begin{array}{l}36.3 \\
(0.72)\end{array}$ & & \\
\hline Wage index & & & & $\begin{array}{l}23.1 \\
(0.64)\end{array}$ & $\begin{array}{l}29.7 \\
(0.72)\end{array}$ & & $\begin{array}{l}81.5 \\
(4.9)\end{array}$ \\
\hline Short interest rate & & & & & & $\begin{array}{l}65.5 \\
(1.6)\end{array}$ & \\
\hline Long interest rate & & & & & & $\begin{array}{l}55.3 \\
(2.4)\end{array}$ & $\begin{array}{l}91.1 \\
(6.1)\end{array}$ \\
\hline Equity price index & & $\begin{array}{l}8.00 \\
(0.07)\end{array}$ & & & & & \\
\hline Dividend yield & & $\begin{array}{l}8.76 \\
(0.11)\end{array}$ & $\begin{array}{l}12.6 \\
(0.20)\end{array}$ & $\begin{array}{l}21.3 \\
(0.76)\end{array}$ & $\begin{array}{l}30.4 \\
(1.4)\end{array}$ & & \\
\hline Population & & & & & $\begin{array}{l}29.2 \\
(0.94)\end{array}$ & $\begin{array}{l}65.2 \\
(3.1)\end{array}$ & \\
\hline Corporate bond yield & & $\begin{array}{l}7.29 \\
(0.19)\end{array}$ & & & & & \\
\hline Equity total return index & & & & & & & $\begin{array}{l}102.2 \\
(13.1)\end{array}$ \\
\hline
\end{tabular}


Table 2c

Significant cycles for the Netherlands

\begin{tabular}{|c|c|c|c|c|c|c|}
\hline Variable & \multicolumn{6}{|c|}{ Cycles (standard errors) } \\
\hline National product index & & $\begin{array}{l}13.1 \\
(0.29)\end{array}$ & & & & \\
\hline Industrial production index & & $\begin{array}{l}10.4 \\
(0.29)\end{array}$ & & & & \\
\hline Employment & & $\begin{array}{l}10.1 \\
(0.08)\end{array}$ & $\begin{array}{l}16.0 \\
(0.22)\end{array}$ & $\begin{array}{l}23.3 \\
(0.33)\end{array}$ & & $\begin{array}{l}50.4 \\
(0.65)\end{array}$ \\
\hline Consumer price index & & $\begin{array}{l}12.8 \\
(0.16)\end{array}$ & $\begin{array}{l}14.7 \\
(0.29)\end{array}$ & $\begin{array}{l}28.0 \\
(0.98)\end{array}$ & $\begin{array}{l}35.0 \\
(1.3)\end{array}$ & \\
\hline Wage index & & no cycl & & & & \\
\hline Short interest rate & & & & & & $\begin{array}{l}64.1 \\
(4.2)\end{array}$ \\
\hline Long interest rate & & $\begin{array}{l}8.91 \\
(0.09)\end{array}$ & & & & $\begin{array}{l}61.2 \\
(5.4)\end{array}$ \\
\hline Equity price index & $\begin{array}{l}4.92 \\
(0.03)\end{array}$ & $\begin{array}{l}10.1 \\
(0.10)\end{array}$ & $\begin{array}{l}14.4 \\
(0.29)\end{array}$ & & $\begin{array}{l}42.3 \\
(2.3)\end{array}$ & \\
\hline Dividend yield & $\begin{array}{l}6.81 \\
(0.05)\end{array}$ & & & & & \\
\hline Population & & $\begin{array}{l}10.7 \\
(0.14)\end{array}$ & $\begin{array}{l}18.3 \\
(0.43)\end{array}$ & & & $\begin{array}{l}61.6 \\
(4.0)\end{array}$ \\
\hline
\end{tabular}


Table 2d

Significant cycles for various variables

\begin{tabular}{|c|c|c|c|c|c|}
\hline Variable & \multicolumn{5}{|c|}{ Cycles (standard errors) } \\
\hline Wholesale Price Index UK 1750-1975 & $\begin{array}{l}8.98 \\
(0.07)\end{array}$ & & & & \\
\hline Wholesale Price Index France 1798-1975 & $\begin{array}{l}10.0 \\
(0.11)\end{array}$ & & $\begin{array}{l}28.1 \\
(0.59)\end{array}$ & & \\
\hline Wholesale Price Index Germany 1792-1918 & $\begin{array}{l}9.12 \\
(0.09)\end{array}$ & $\begin{array}{l}12.4 \\
(0.27)\end{array}$ & & $\begin{array}{l}62.4 \\
(5.4)\end{array}$ & \\
\hline Wholesale Price Index US 1801-1975 & $\begin{array}{l}9.24 \\
(0.07)\end{array}$ & $\begin{array}{l}13.4 \\
(0.20)\end{array}$ & $\begin{array}{l}27.6 \\
(0.74)\end{array}$ & $\begin{array}{l}52.2 \\
(3.7)\end{array}$ & \\
\hline South English Real Wages 1736-1954 & $\begin{array}{l}8.84 \\
(0.04)\end{array}$ & & $\begin{array}{l}35.9 \\
(1.62)\end{array}$ & & \\
\hline South English Consumer Price Index 1495-1998 & $\begin{array}{l}9.00 \\
(0.03)\end{array}$ & $\begin{array}{l}14.85 \\
(0.10)\end{array}$ & $\begin{array}{l}35.8 \\
(0.56)\end{array}$ & & \\
\hline Innovations $^{7}$ & 5 & 13 & 24 & 34 & 61 \\
\hline
\end{tabular}

\footnotetext{
${ }^{7}$ The cycles were fixed in the linear count data regression model in De Groot and Franses (2005), so no standard errors are available.
} 
Table 3

Bayesian Information Criteria values for mixtures of normal distributions

(smallest values are underlined)

70 cycles

\begin{tabular}{clrc}
\hline \hline & & & \\
& & Variance & \\
Number of distributions & Common & All different & First different from rest \\
3 & 8.868 & 8.866 & 8.806 \\
4 & 8.803 & 8.863 & $\underline{8.775}$
\end{tabular}

90 cycles

\begin{tabular}{clrc}
\hline \hline & & & \\
& \multicolumn{3}{c}{ Variance } \\
Number of distributions & Common & All different & First different from rest \\
3 & 8.770 & 8.573 & 8.587 \\
4 & 8.590 & 8.615 & $\underline{8.535}$
\end{tabular}


Table 4a: Mixtures of normal distributions for 70 cycle lengths

\begin{tabular}{clll}
\hline \hline & & & \\
Distribution & Mean & Variance & Probability \\
\hline \hline & & & \\
1 & 10.3 & 3.5 & 0.576 \\
2 & 25.7 & 8.0 & 0.190 \\
3 & 57.7 & 8.0 & 0.192 \\
4 & 92.0 & 8.0 & 0.042 \\
\hline \hline
\end{tabular}

Table 4b: Mixtures of normal distributions for 90 cycle lengths

\begin{tabular}{clll}
\hline \hline & & & \\
Distribution & Mean & Variance & Probability \\
\hline \hline & & & \\
1 & 10.4 & 3.3 & 0.483 \\
2 & 27.9 & 7.3 & 0.191 \\
3 & 58.3 & 7.3 & 0.294 \\
4 & 91.9 & 7.3 & 0.032 \\
\hline \hline
\end{tabular}



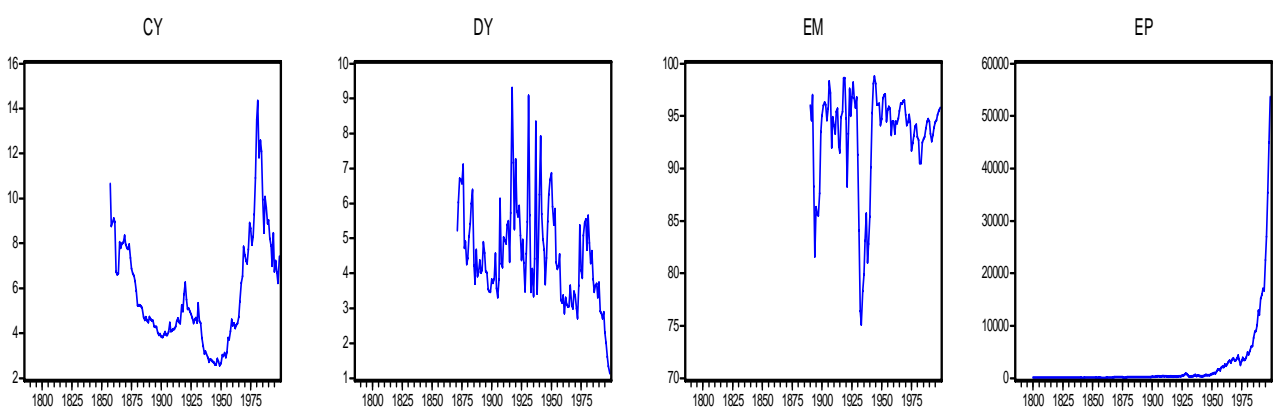

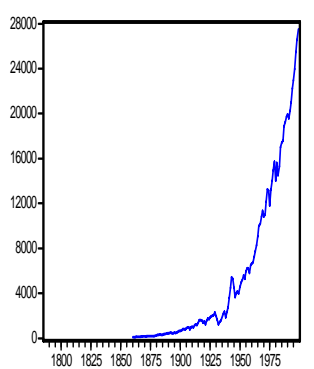

POP

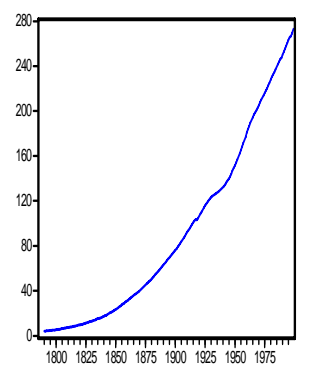

LR

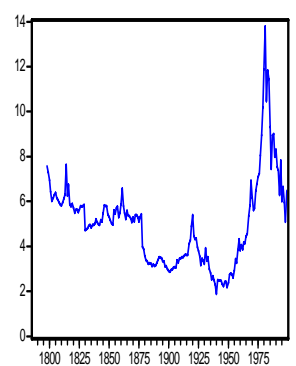

SR

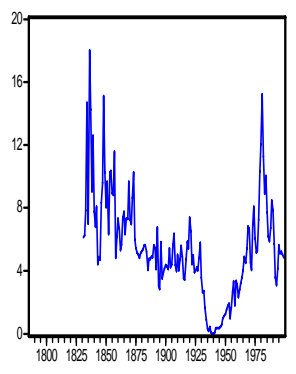

NP

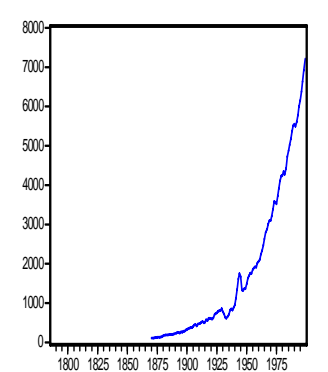

WI

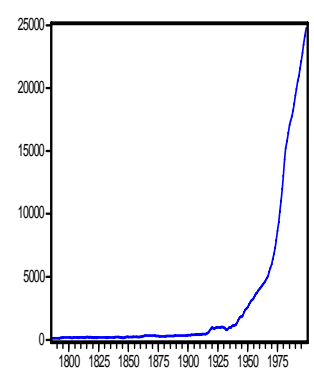

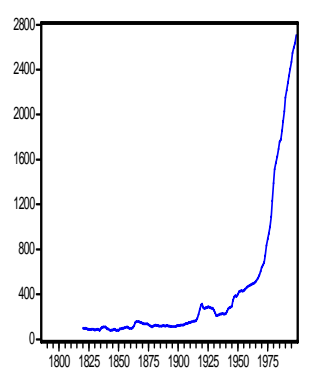

Figure 1a: Annual time series, The United States 
$\mathrm{CY}$

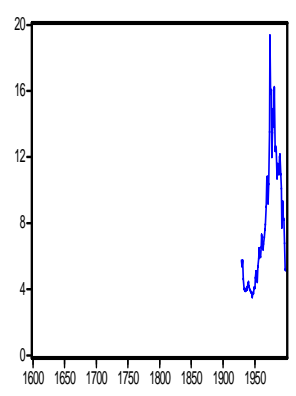

ET

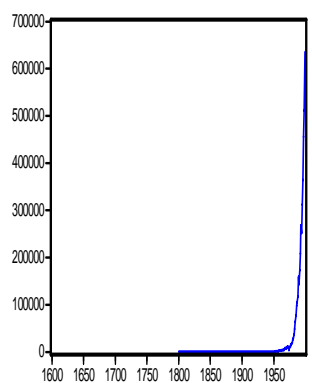

$\mathrm{Pl}$

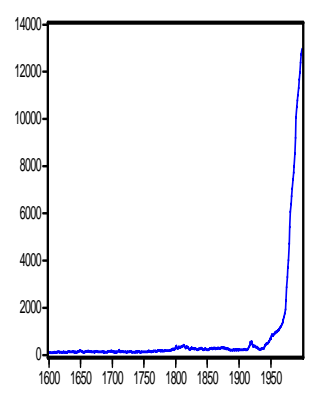

DY

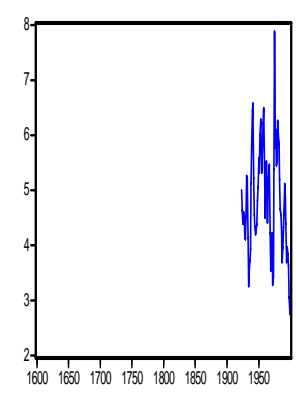

$\mathbb{P}$

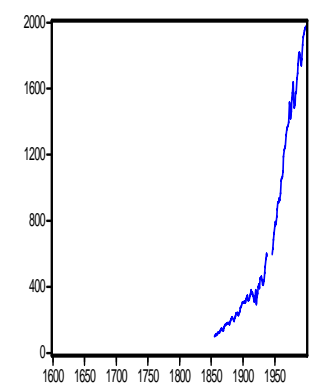

POP

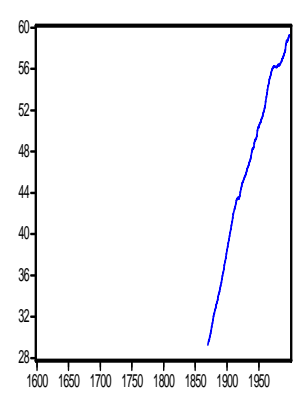

EM

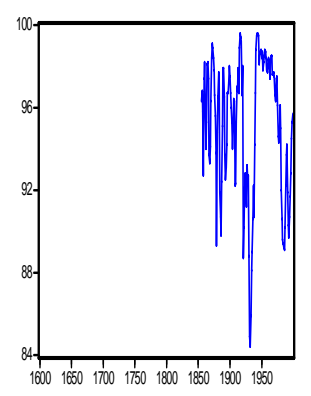

LR

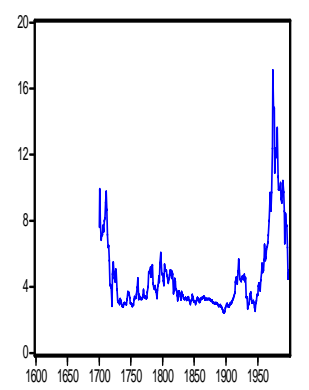

SR

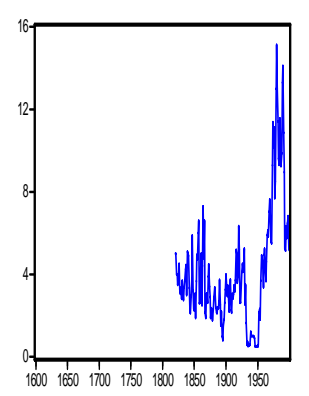

EP

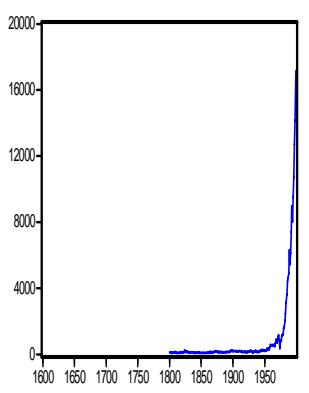

NP

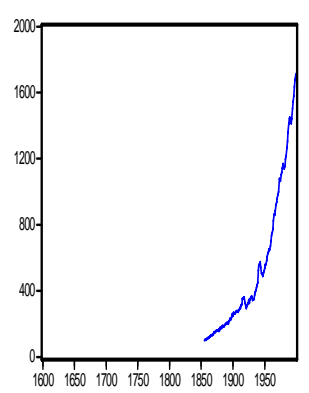

WI

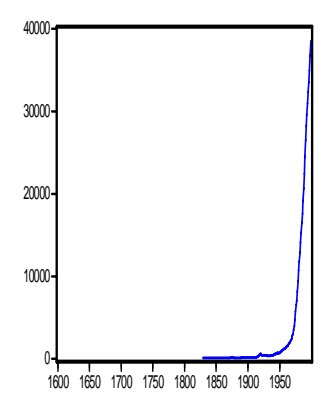

Figure 1b: Annual time series, The United Kingdom 

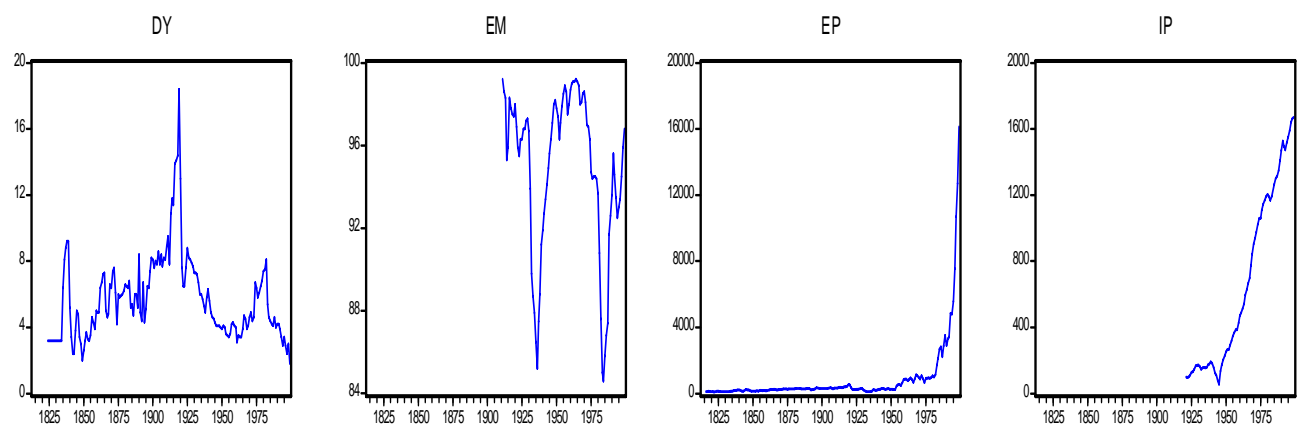

LR

NP
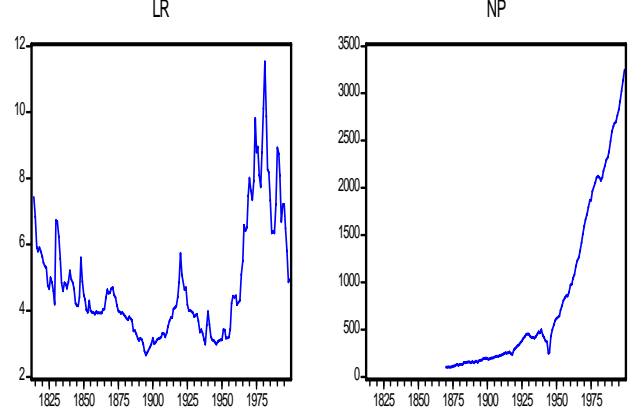

PI

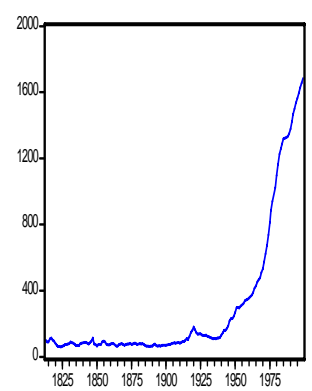

POP

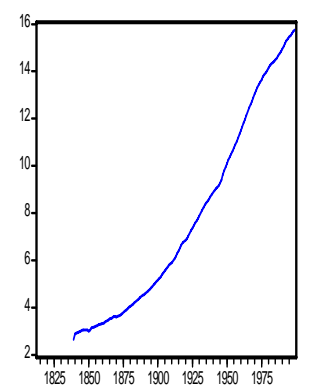

$S R$
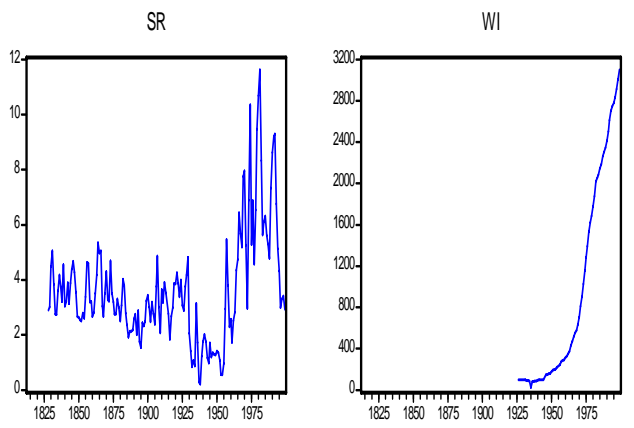

Figure 1c: Annual time series, The Netherlands 


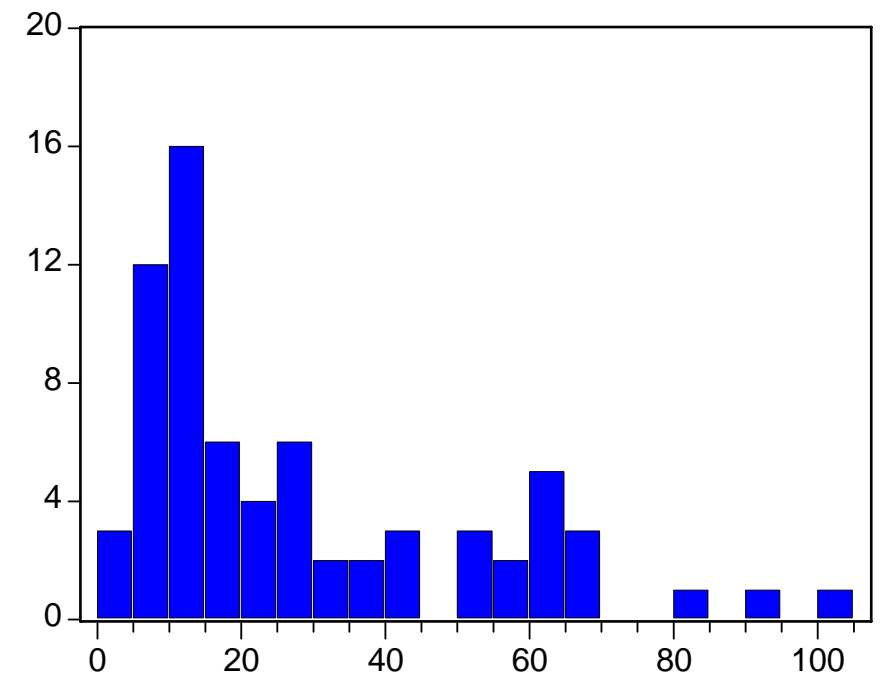

Series: CYCLES

Sample 170

Observations 70

Mean $\quad 28.32900$

Median $\quad 18.75000$

Maximum $\quad 102.2000$

Minimum $\quad 4.780000$

Std. Dev. $\quad 23.34475$

Skewness $\quad 1.165479$

Kurtosis $\quad 3.559063$

Jarque-Bera $\quad 16.75893$

Probability $\quad 0.000230$

Figure 2a: 70 cycles 


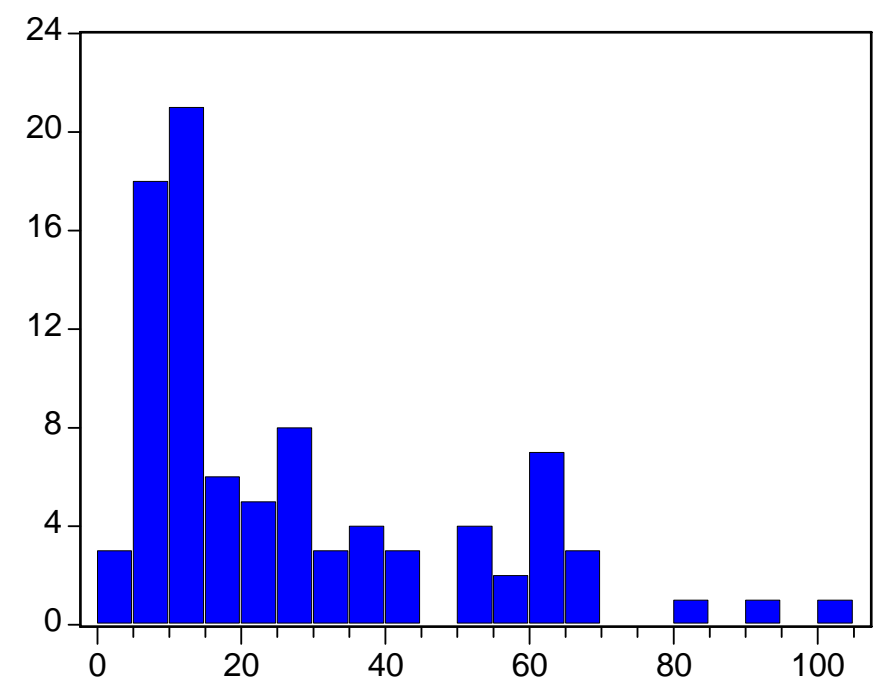

Series: $Y$

Sample 190

Observations 90

Mean 27.31033

Median $\quad 18.25000$

Maximum $\quad 102.2000$

Minimum $\quad 4.780000$

Std. Dev. $\quad 22.26138$

Skewness $\quad 1.199791$

Kurtosis $\quad 3.724995$

Jarque-Bera $\quad 23.56354$

Probability $\quad 0.000008$

Figure 2b: 90 cycles 


\section{LITERATURE}

Bak P., Tang C. and Wiesenfeld K. (1987), Self-organized Criticality: An Explanation of the 1/f Noise, Physical Review Letters, 59, 381-384.

Davies, R.B. (1977), Hypothesis testing when a nuisance parameter is present only under the alternative, Biometrika, 64, 247-254.

De Groot, E.A. and P.H. Franses (2005), Cycles in basic innovations, Econometric Institute Report 2005-34, Erasmus University Rotterdam.

Duijn, J.J. van (1983), The Long Wave in Economic Life, London: George Allen and Unwin.

Freeman, C., (1996, ed.), Long wave theory, Cheltenham, UK: Edward Elgar.

Freeman, C, and F. Louca (2001), As Time goes by. From Industrial Revolutions to the Information Revolution, Oxford: Oxford University Press.

Goldstein, J.S. (1988), Long Cycles: Prosperity and War in the Modern Age, New Haven: Yale University Press.

Goodwin, R.M. (1991) Economic Evolution, Chaotic Dynamics and the MarxKeynes-Schumpeter System, Chapter 9 in Hodgson, G. M. en Screpanti, E. (eds.), Rethinking Economics: Markets, Technology and Economic Evolution, Cheltenham UK: Edward Elgar, 138-52.

Haustein, H.-D. and Neuwirth, E. (1982), Long Waves in World Industrial Production, Energy Consumption, Innovations, Inventions, and Patents and Their Identification by Spectral Analysis, Technological Forecasting and Social Change, $22,53-89$. 
Klimenko, L. en Menshikov, S. (1987), Catastrophe Theory Applied to the Analysis of the Long Wave, Chapter 25 in Vasko, T. (ed.), The Long Wave Debate, Berlin: Springer-Verlag, 345-58.

Koshy, T. (2001), Fibonacci and Lucas Numbers with Applications, New York: John Wiley and Sons.

Kuczynski, Th. (1978), Spectral Analysis and Cluster Analysis as Mathematical Methods for the Periodization of Historical Processes, 7th International Economic History Congress, Edinburgh.

Kuznets, S. (1940), Schumpeter's Business Cycles, American Economic Review, 30, 257-271.

Lorenz E.M. (1963), Deterministic Nonperiodic Flow, Journal of the Atmospheric Sciences, 20, 130-141.

Louçã, F., and J. Reijnders (1999, eds.), The Foundations of Long Wave Theory; Models and Methodology, Cheltenham, UK: Edward Elgar.

Koshy, T. (2001), Fibonacci and Lucas Numbers with Applications, New York: John Wiley and Sons.

Mandelbrot, B. (1977), Fractals and Scaling in Finance, New York: Springer.

Mandelbrot, B. (1982), The Fractal Geometry of Nature, New York, Freeman and Co.

Mantegna R.N. and H.E. Stanley (2000), An Introduction to Econophysics, Cambridge UK: Cambridge University Press.

Marchetti, C. (1980), Society as a Learning System: Discovery, Invention, and Innovation Cycles Revisited, Technological Forecasting and Social Change, 18, $267-$ 282. 
Matutinović I. (2001), The Aspects and the Role of Diversity in Socioeconomic Systems: An Evolutionary Perspective, Ecological Economics, 39, 239-256.

Matutinović I. (2002), Organizational Patterns of Economies: An Ecological Perspective, Ecological Economics, 40, 421-440.

McCauley J.L. (2004), Dynamics of Markets: Econophysics and Finance, Cambridge UK: Cambridge University Press.

Modelski, G and W. Thompson (1996), Leading Sectors end World Powers: The Coevolution of Global Economics and Politics, Columbia: University of South Carolina Press.

Reijnders, J. (1990), Long Waves in Economic Development, Cheltenham UK: Edward Elgar.

Roehner B.M. (2004), Patterns of Speculation, A Study in Observational Econophysics, Cambridge UK: Cambridge University Press.

Schumpeter J. (1939), Business Cycles: A Theoretical, Historical and Statistical Analysis of the Capitalistic Process, New York: McGraw-Hill.

Silverberg, G. and D. Lehnert (1996), Evolutionary Chaos: Growth Fluctuations in a Schumpeterian Model of Creative Destruction, Chapter 2 in Barnett, W.A., Kirman, A.P. en Salmon, M. (eds.), Nonlinear Dynamics and Economics, Cambridge UK: Cambridge University Press, 45-74.

Silverberg, G. and B. Verspagen (2000), Breaking the Waves: A Poisson Regression Approach to Schumpeterian Clustering of Basic Innovations, Cambridge Journal of Economics, 27, 671-693.

Schumpeter J. (1939), Business Cycles: A theoretical, historical and statistical analysis of the Capitalistic process, New York: McGraw-Hill. 
Steehouwer, H. (2005), Macroeconomic Scenarios and Reality, PhD Thesis, Free University Amsterdam.

Thio, K.B.T. (1991), On Simultaneous Explanation of Long and Medium-term Employment Cycles, De Economist, 139, 331-357. 